\title{
Ciclos de seleção de progênies de meios-irmãos do milho BR 5011 Sertanejo
}

\author{
Hélio Wilson Lemos de Carvalho(1) e Evanildes Menezes de Souza(1) \\ (1)Embrapa Tabuleiros Costeiros, Av. Beira-Mar, 3.250, Caixa Postal 44, CEP 49001-970 Aracaju, SE. E-mail: helio@cpatc.embrapa.br, \\ evanildes@gmail.com
}

\begin{abstract}
Resumo - O objetivo deste trabalho foi obter estimativas de parâmetros genéticos da variedade BR 5011 Sertanejo, a fim de se avaliar o comportamento da variabilidade genética, no decorrer de sucessivos ciclos de seleção. Dezessete ciclos de seleção, entre e dentro de progênies de meios-irmãos, e três ciclos de seleção massal estratificada foram praticados nessa variedade de milho, no período de 1985 a 2005. Nos três primeiros ciclos de seleção, entre e dentro de progênies de meios-irmãos, as progênies foram avaliadas em látice 10x10, e entre os ciclos 4 e 17, as avaliações foram realizadas em látice 14x14. Os ensaios foram realizados nos municípios de Gararu, Propriá, Poço Verde, Neópolis, Lagarto e Nossa Senhora das Dores, no Estado de Sergipe, e em Cruz das Almas na Bahia. As parcelas constaram de fileiras de $5 \mathrm{~m}$, espaçadas de 0,8 m, com 0,4 m entre covas dentro das fileiras. As recombinações das progênies superiores foram realizadas dentro do mesmo ano agrícola, de modo a se obter um ciclo por ano. A variedade BR 5011 Sertanejo apresentou alto potencial produtivo, associado a uma ampla base genética. A magnitude da interação progênies x locais evidenciou a importância de se avaliar a produtividade em mais de um local para melhorar a eficiência do processo seletivo e para se obterem estimativas mais consistentes dos componentes da variância.
\end{abstract}

Termos para indexação: Zea mays, ganhos genéticos, seleção entre e dentro, seleção massal.

\section{Selection cycles of half-sib families for the maize variety BR 5011 Sertanejo}

\begin{abstract}
The objective of this work was to estimate the genetic parameters of the maize variety BR 5011 Sertanejo, in order to evaluate the behavior of the genetic variability along successive selection cycles. Seventeen betweenand within-half-sib family selection cycles and three stratified mass selections were carried out for this maize variety, between 1985 and 2005. In the three first selection cycles of between- and within-half-sib families, families were evaluated using a 10x10 lattice, whereas for the reminder of the cycles, a 14x14 lattice was employed. The assays were carried out in the municipalities of Gararu, Propriá, Poço Verde, Neópolis, Lagarto and Nossa Senhora das Dores, in Sergipe State, and at Cruz das Almas, Bahia State. The plots were composed by $5 \mathrm{~m}$ rows spaced at $0.8 \mathrm{~m}$, and within-row spacing of $0.4 \mathrm{~m}$. The recombination of the selected families was made within the same agricultural year, as to get one cycle per year. The maize variety BR 5011 Sertanejo presented a high yield potential and a wide genetic variability. The highly significant family $\mathrm{x}$ site interaction highlighted the importance of evaluating productivity across multiple sites, in order to improve the efficiency of selection process and get more reliable estimates of variance components.
\end{abstract}

Index terms: Zea mays, genetic gain, between and within selection, mass selection.

\section{Introdução}

O milho assume papel de destaque na economia da Região Nordeste do Brasil por sua importância na alimentação humana e animal, principalmente de aves e suínos. O aumento no consumo tem causado problemas no abastecimento regional, pois a quantidade de grãos produzida não atende à demanda, o que torna necessário a busca do produto em outras regiões do país e no exterior. Além disso, a produtividade do milho na região é baixa por causa, principalmente, da instabilidade pluvial, das altas temperaturas, do baixo nível tecnológico dos produtores e da insuficiência de sementes melhoradas de variedades adaptadas.

O mercado para variedades de milho nessa ampla região é crescente, e a cultura ocupa cerca de dois milhões de hectares, distribuídos em áreas dos Tabuleiros Costeiros, Agreste e Sertão. Diante desse fato, e considerando-se que variedades adaptadas representam fator preponderante para promover melhoria de 
produtividade nos sistemas de produção, e que sementes melhoradas constituem um dos insumos mais baratos, desenvolveu-se um programa de melhoramento voltado para a obtenção de variedades direcionadas para as áreas dos Tabuleiros Costeiros, Agreste e Sertão.

Para áreas do agreste, foram desenvolvidas e recomendadas as variedades Asa Branca (Carvalho et al., 2001) e São Francisco (Carvalho et al., 2003a), ambas de ciclo precoce e com produtividade de até $6.000 \mathrm{~kg} \mathrm{ha}^{-1}$. Para áreas do sertão, onde a superprecocidade constitui forte justificativa para reduzir riscos de frustração de safras, as variedades superprecoces BRS-Caatigueiro (Carvalho et al., 2002) e Assum Preto (Carvalho et al., 2003b) foram desenvolvidas. A variedade Sertanejo, de ciclo semiprecoce, vem sendo desenvolvida ao longo de 20 anos, com direcionamento para áreas do Agreste e dos Tabuleiros Costeiros.

Entre os vários métodos de seleção intrapopulacional para aumentar a freqüência de alelos favoráveis nas populações, o de seleção entre e dentro de progênies de meios-irmãos tem-se mostrado eficiente, pois permite a obtenção de progressos genéticos de forma mais rápida, pela possibilidade de realização de um ciclo por ano (Hallauer \& Miranda Filho, 1988). A análise dos dados do teste de progênies permite estimar a variância genética aditiva na população base e, em conseqüência, verificar quais as chances de êxito na seleção.

Muitos trabalhos na literatura relatam uma quantidade suficientemente grande de variância genética aditiva em populações de polinização aberta de milho, para o caráter produção de grãos (Packer, 1998). As estimativas dessa variância são realizadas, em grande parte, utilizando-se de progênies de meios-irmãos, de onde se estimam também, a herdabilidade e o ganho por seleção. Resultados satisfatórios, quanto aos ganhos esperados em produtividade de espigas, vêm sendo obtidos no Nordeste brasileiro com a variedade BR 5033Asa Branca (Carvalho et al., 2000a, 2001, 2005a); com a variedade BR 5028-São Francisco (Carvalho et al., 1998, 2003a); com a variedade BRS Assum Preto (Carvalho et al., 2003b); com a população CPATC-3 (Carvalho et al., 2003c, 2005b); com as populações CMS-47 e BR 5039 (Cardoso et al., 2003), cuja seleção entre e dentro de progênies de meios-irmãos vem sendo realizada sem sementes remanescentes (um ciclo por ano), o que, segundo Ramalho (1977), proporciona ganhos anuais maiores do que com o uso de sementes remanescentes (um ciclo a cada dois anos). Esse autor enfatizou que, em ciclos subseqüentes de seleção entre e dentro de progênies de meios-irmãos, deve-se dar maior ênfase à seleção entre progênies do que dentro de progênies.

O objetivo deste trabalho foi obter estimativas de parâmetros genéticos na variedade de milho BR 5011 Sertanejo, a fim de se verificar o comportamento da variabilidade genética no decorrer de sucessivos ciclos de seleção.

\section{Material e Métodos}

A população Pool 21 do CIMMYT (Centro Internacional de Mejoramento de Maíz y Trigo) foi introduzida no Brasil em 1975, pela Embrapa Milho e Sorgo, e recebeu a denominação de CMS-11, após sofrer um ciclo de seleção massal no ano agrícola de 1976/1977. Nos anos agrícolas de 1978/1979 e 1979/1980, essa população passou por dois ciclos de seleção entre e dentro de progênies de irmãos germanos, em Sete Lagoas, MG. Em 1981/1982 foram avaliadas 400 progênies $S_{2}$, obtidas das melhores progênies de irmãos germanos, também em Sete Lagoas. Introduzida no Nordeste brasileiro em 1982, foi avaliada em diferentes áreas produtoras de milho (municípios de Poço Verde e Nossa Senhora das Dores, Agreste sergipano; Caruaru, no Agreste pernambucano e Araripina no Sertão de Pernambuco; e Cruzeta e Apodi no Agreste do Rio Grande do Norte), demonstrou possuir bom potencial para a produção de grãos e foi escolhida para ser submetida ao programa de melhoramento intrapopulacional de milho para a Região Nordeste do Brasil, com a denominação de BR 5011 Sertanejo.

Trata-se de uma variedade de milho de polinização aberta, com florescimento masculino aos 61 dias e colheita aos 130 dias. Apresenta altura média de planta entre 2,00 e 2,60 m e altura média de inserção da primeira espiga entre 2,30 e 1,50 m, com bom empalhamento das espigas, boa tolerância ao acamamento e ao quebramento do colmo, e produção de grãos média de 4,5 t ha $^{-1}$ de grãos semiduros com coloração amarelointensa.

No ano agrícola de 1984, foi plantada uma área de $2.000 \mathrm{~m}^{2}$ desse material, no Município de Gararu, SE, onde foram obtidas 200 progênies de meios-irmãos, com base nas boas características de altura de planta e espigas, resistência ao acamamento, prolificidade, 
empalhamento, tipo e coloração de grãos e disposição das fileiras na espiga. A seguir, foram realizados três ciclos de seleção entre e dentro de progênies de meiosirmãos, cujo ciclo 1 foi realizado no Município de Gararu em 1985, e os ciclos 2 e 3, respectivamente, nos anos de 1986 e 1987, nos municípios de Propriá e Poço Verde, também em Sergipe. Em cada um desses ciclos, foram avaliadas 200 progênies em dois látices simples 10x10, com as progênies de 1 a 100 colocadas no ensaio A, e de 101 a 200, no ensaio B.

Entre 1988 e 1990, essas populações passaram por três ciclos de seleção massal estratificada quanto aos caracteres altura de planta e de inserção da primeira espiga, empalhamento, acamamento e quebramento do colmo, e coloração de grãos, no Estado de Sergipe. No último ciclo de seleção massal, em 1990, foram selecionadas 196 progênies quanto aos caracteres já mencionados, para reiniciar o programa de melhoramento, tendo-se utilizado o esquema de seleção entre e dentro de progênies de meios-irmãos, em látice simples $14 \times 14$.

A seguir, foram realizados os ciclos 4 e 5, nos anos de 1991 e 1992, no Município de Neópolis; o ciclo 6, em 1993, em Neópolis e Umbaúba; o 7, em 1994, em Lagarto; o 8, em Neópolis, Lagarto e Cruz das Almas, BA, em 1995; o 9, em 1996, em Nossa Senhora das Dores e Neópolis; o 10, em 1997, em Nossa Senhora das Dores e Umbaúba; o 11, em 1998, em Neópolis e Umbaúba; os ciclos 12 e 13, em 1999 e 2000, nos municípios de Neópolis e Nossa Senhora das Dores, respectivamente; o 14, em 2001, em Neópolis e em dois ambientes no Município de Nossa Senhora das Dores; os ciclos 15, 16 e 17, foram realizados, nos anos agrícolas de 2002, em Simão Dias e Nossa Senhora das Dores, 2003, em Simão Dias e Nossa Senhora das Dores, e 2004, em Simão Dias.

Do ciclo 1 ao ciclo 3, cada parcela constou de uma fileira de $5 \mathrm{~m}$ de comprimento, espaçadas de $1 \mathrm{~m} \mathrm{e}$ $0,50 \mathrm{~m}$ entre covas dentro das fileiras; do ciclo 4 ao 17 , as parcelas foram constituídas por fileiras de $5 \mathrm{~m}$ de comprimento, espaçadas de $0,90 \mathrm{~m}$, com $0,40 \mathrm{~m}$ entre covas dentro das fileiras. Foram colocadas três sementes por cova, tendo-se deixado duas plantas por cova, após o desbaste. A variedade testemunha BR 106 foi colocada sistematicamente dentro de cada bloco, somando 14 parcelas em cada repetição. As adubações realizadas em cada ensaio foram baseadas nos resultados das análises de solo de cada área experimental.
Cada ciclo foi completado pela seleção das 20 progênies superiores, tendo-se considerado o peso de grãos entre os ciclos 1 e 3 e o peso de espigas entre os ciclos 4 e 17, que foram recombinadas em lotes isolados por despendoamento, com as fileiras femininas (despendoadas) representadas pelas progênies selecionadas, e as masculinas representadas pela mistura das mesmas. Foram selecionadas 200 novas progênies, nos ciclos 2 e 3, e 196 progênies, entre os ciclos 4 e 17, correspondentes à intensidade de seleção de $10 \%$ entre e $10 \%$ dentro do mesmo ano agrícola.

Nos três primeiros ciclos de seleção, foi considerada apenas a característica peso de grãos por planta e, nos ciclos subseqüentes (do 4 ao 17), consideraram-se os pesos de espigas, corrigidas para $15 \%$ de umidade. No ano agrícola de 1985, quando as progênies foram avaliadas em um só local, as análises de variância foram feitas para cada látice em separado. A seguir, os quadrados médios para tratamento foram ajustados e o erro efetivo dos dois látices foi ponderado, tendo originado as análises agrupadas. Nos ciclos 2 e 3, com avaliações feitas em dois locais, além das análises individuais e agrupadas dentro de cada local, foram feitas as análises de variância conjunta para locais, que englobou os ensaios que possuíam as mesmas 100 progênies, tendo-se utilizado as médias ajustadas das progênies, conforme o modelo do delineamento de blocos ao acaso (Vianna \& Silva, 1978). Finalmente, foi feita a ponderação dos quadrados médios para progênies, da interação progênies x locais, e dos erros combinados das análises conjuntas, para reagrupar as 200 progênies numa só análise, denominada análise agrupada (Pacheco, 1987).

As estimativas dos parâmetros genéticos (variância entre progênies, variância aditiva, variância da interação progênies x locais, coeficiente de herdabilidade, coeficiente de variação genética, índice b e ganhos); dentro de cada local e na média dos locais, foram obtidas das análises combinadas e agrupadas, respectivamente, as quais tiveram os seus quadrados médios ajustados para indivíduos, obtendo-se, assim, as variâncias expressas em (g por planta) ${ }^{2}$ (Vencovsky, 1987). Embora as análises tenham sido feitas em látice, as estimativas dos componentes da variância foram baseadas nas esperanças dos quadrados médios para blocos ao acaso, tendo-se usado os quadrados médios de tratamentos ajustados e o erro efetivo do látice (Vianna \& Silva, 1978). 
Do ciclo 4 ao 17, em que as progênies foram avaliadas em látice $14 x 14$, foram realizadas, inicialmente, as análises de variância por ensaio, tendo-se obedecido o esquema em látice. Nos ciclos com ensaios realizados em mais de um local, procedeu-se à análise de variância conjunta agrupada, a partir das médias ajustadas de tratamento, tendo-se considerado aleatório o efeito de locais. Os locais utilizados foram: Nossa Senhora das Dores, em áreas dos Tabuleiros Costeiros; e Simão Dias, em áreas do Agreste. Os quadrados médios das análises de variância, por local e conjunta, foram ajustados para indivíduos, tendo-se obtido todas as variâncias desses níveis expressas em (g por planta) ${ }^{2}$, conforme Vencovsky (1987). Na estimação dos componentes da variância, utilizaram-se os métodos descritos por Vianna \& Silva (1978).

\section{Resultados e Discussão}

A análise de variância agrupada da característica peso de grãos, observada em progênies da população 1 , revelou diferenças significativas a $1 \%$ de probabilidade. Nas análises de variância agrupada entre locais, com dados provenientes de observações de progênies dos ciclos 2 e 3 , foram detectados efeitos significativos $(\mathrm{p}<0,01)$, em relação aos efeitos de progênies, locais e progênies x locais, o que revela comportamento diferenciado entre as progênies, os locais e a presença de diferenças no comportamento das progênies, em relação aos vários locais.

As evidências amostrais, dos ciclos 4 ao 17, indicaram diferenças estatisticamente significativas $(p<0,01)$, pelo teste $\mathrm{F}$, entre progênies obtidas da população base, quanto à característica peso de espigas. Nos ciclos com avaliações em mais de um local, obteve-se efeito estatisticamente significativo a $1 \%$ de probabilidade pelo teste $\mathrm{F}$, de interação progênies x locais, o que mostra comportamento inconsistente das progênies em relação aos ambientes. Os valores dos coeficientes de variação, das características peso de grãos (ciclos 1 ao 3) e de espigas (ciclos 4 ao 17), oscilaram de 8 a $18 \%$, o que indica boa precisão dos experimentos (Scapim et al., 1995).

A produtividade média de espigas obtidas nas progênies avaliadas dos ciclos 4 ao 17 variou de 6.024 a $8.340 \mathrm{~kg} \mathrm{ha}^{-1}$, com média de $6.813 \mathrm{~kg} \mathrm{ha}^{-1}$ de espigas, o que atesta $\mathrm{o}$ alto potencial genético para produtividade de espigas dessa variedade (Tabela 1). As progênies selecionadas superaram a testemunha BR $106 \mathrm{em}$ todos os ciclos de seleção, o que evidencia um melhoramento considerável na variedade Sertanejo.
A amplitude da produtividade média observada entre as progênies de cada ciclo (Tabela 1), embora tenha pouco valor para medir a variabilidade existente no material (Paterniani, 1968), permite visualizar os níveis de produtividade relativamente elevados que certas progênies apresentaram, quando chegaram a produzir, no ciclo 17 , cerca de $90 \%$ mais que a variedade testemunha, o que revela que progênies superiores foram obtidas com o desenvolver dos novos ciclos de seleção.

Quanto ao comportamento das estimativas dos parâmetros genéticos da variedade BR 5011 Sertanejo, houve decréscimo da variabilidade do ciclo 1 para os ciclos 2 e 3 (Tabela 2). Essa tendência foi também observada por Carvalho et al. (2000a, 2000b, 2001, 2003c) e ressaltada por Ramalho (1977), como consequiência da utilização máxima da variabilidade livre, existente no ciclo original, que corresponde à segregação de blocos poligênicos. A partir do primeiro ciclo de seleção, é utilizada a variabilidade genética latente, presente dentro de blocos poligênicos, que é liberada gradativamente por meio da permuta gênica.

A população 1 apresentou os maiores valores de variância entre progênies de meios-irmãos (Tabela 2). Com um ciclo de seleção, o valor dessa variância diminuiu sensivelmente, em razão não só da exploração da variabilidade livre no ciclo 1 , mas também pelo fato de as progênies desse ciclo de seleção terem sido avaliadas em dois locais, o que tornou as estimativas menos influenciadas pelo componente da interação progênies $\mathrm{x}$ locais. As estimativas dos parâmetros genéticos (variância genética entre progênies, variância genética aditiva, coeficiente de herdabilidade, no sentido restrito de média entre progênies e quanto à seleção massal, coeficiente de variação genética, índice b e ganhos entre e dentro de progênies), referentes ao ciclo 3 , foram drasticamente reduzidas em relação aos ciclos 1 e 2 , o que pode ser explicado pelo estresse de umidade, que provocou redução na produtividade, com reflexo na magnitude das estimativas desses parâmetros (Hallauer \& Miranda Filho, 1988). As estimativas dessa variância, a partir do ciclo 4 de seleção, não mostraram queda no decorrer dos ciclos seguintes de seleção, quando esta foi realizada em um só local. Verificou-se uma redução acentuada nas estimativas da variância, quando a seleção foi realizada na média de dois e três locais, porque nesses casos foi isolada a influência de interação progênies x locais (Tabela 2).

A variação detectada na variância genética aditiva acompanhou a estimada na variância genética entre 
progênies, em todos os ciclos de seleção, tendo-se registrado os valores mais elevados nos ciclos 4, 5, 7 e 17, quando a seleção foi efetuada em apenas um local. Apesar de as estimativas obtidas nesses ciclos serem influenciadas pela interação progênies x locais, os valores elevados nos ciclos 1 e 4 ocorreram, também, graças à exploração da variabilidade livre, presente nesses ciclos de seleção, que superaram os valores relatados por Carvalho et al. (2003a, 2005b). Paterniani (1968) ressalta que é do máximo interesse que a variância genética aditiva permaneça tão alta quanto possível, para permitir progressos substanciais por seleção.

As estimativas da variância da interação progênies $\mathrm{x}$ locais evidenciam grande divergência entre os locais, e comportamento diferenciado das progênies nesses locais. Hallauer \& Miranda Filho (1988) comentaram que esses componentes da variância podem atingir mais de 50\% do valor da estimativa da variância genética entre progênies, e que as estimativas de parâmetros genéticos obtidos em apenas um local são superestimadas, em

Tabela 1. Comparação da produtividade média de espigas, das progênies avaliadas e selecionadas da variedade BR 5011 Sertanejo, entre os ciclos 4 e 17 de seleção, com a testemunha BR 106, e médias ajustadas das progênies avaliadas em relação à variedade testemunha.

\begin{tabular}{|c|c|c|c|c|}
\hline Material & $\begin{array}{l}\text { Produtividade média } \\
\left(\mathrm{kg} \mathrm{ha}^{-1}\right)\end{array}$ & $\begin{array}{l}\text { Porcentagem em relação à } \\
\text { testemunha }\end{array}$ & $\begin{array}{l}\text { Produtividade média } \\
\left(\mathrm{kg} \mathrm{ha}^{-1}\right)\end{array}$ & $\begin{array}{l}\text { Porcentagem em relação à } \\
\text { testemunha }\end{array}$ \\
\hline & \multicolumn{2}{|c|}{----------------------------Ciclo 4-------------------------- } & \multicolumn{2}{|c|}{---------------------------'Ciclo 5-------------------------- } \\
\hline BR 106 & 6.907 & 100 & 6.123 & 100 \\
\hline Progênies avaliadas & 6.202 & 90 & 7.216 & 118 \\
\hline Progênies selecionadas & 7.398 & 107 & 8.710 & 142 \\
\hline Amplitude de variação & $3.918-7.882$ & $57-114$ & $3.761-9.545$ & $56-157$ \\
\hline \multirow[t]{2}{*}{ Média ajustada } & 5.365 & & 7.163 & \\
\hline & \multicolumn{2}{|c|}{ |---------------------------Ciclo 6-------------------------- } & \multicolumn{2}{|c|}{ 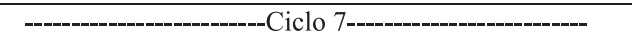 } \\
\hline BR 106 & 7.771 & 100 & 6.533 & 100 \\
\hline Progênies avaliadas & 6.659 & 86 & 8.340 & 128 \\
\hline Progênies selecionadas & 8.605 & 111 & 10.160 & 156 \\
\hline Amplitude de variação & $4.931-8.619$ & $63-111$ & $5.672-11.500$ & $87-176$ \\
\hline \multirow[t]{2}{*}{ Média ajustada } & 4.958 & & 7.877 & \\
\hline & \multicolumn{2}{|c|}{ |-------------------------Ciclo 8-------------------------- } & \multicolumn{2}{|c|}{--------------------------Ciclo 9-------------------------- } \\
\hline BR 106 & 5.507 & 100 & 6.720 & 100 \\
\hline Progênies avaliadas & 6.032 & 110 & 7.232 & 108 \\
\hline Progênies selecionadas & 7.407 & 134 & 8.630 & 128 \\
\hline Amplitude de variação & $3.930-8.541$ & $71-155$ & $5.175-9.189$ & $77-137$ \\
\hline \multirow[t]{2}{*}{ Média ajustada } & 6.595 & & 6.582 & \\
\hline & \multicolumn{2}{|c|}{---------------------------Ciclo 10----------------'--------- } & \multicolumn{2}{|c|}{ 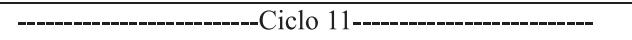 } \\
\hline BR 106 & 5.450 & 100 & 5.710 & 100 \\
\hline Progênies avaliadas & 6.047 & 110 & 6.024 & 105 \\
\hline Progênies selecionadas & 7.285 & 134 & 7.015 & 123 \\
\hline Amplitude de variação & $3.447-8.144$ & $63-149$ & $4.785-7.216$ & $84-126$ \\
\hline \multirow[t]{2}{*}{ Média ajustada } & 6.667 & & 6.384 & \\
\hline & \multicolumn{2}{|c|}{ 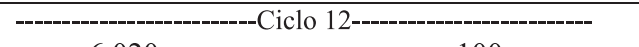 } & \multicolumn{2}{|c|}{ 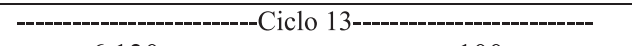 } \\
\hline BR 106 & 6.020 & 100 & 6.130 & 100 \\
\hline Progênies avaliadas & 6.568 & 109 & 6.552 & 107 \\
\hline Progênies selecionadas & 7.954 & 132 & 8.019 & 131 \\
\hline Amplitude de variação & $4.444-8.625$ & $74-143$ & $3.927-9.418$ & $64-154$ \\
\hline \multirow[t]{2}{*}{ Média ajustada } & 6.618 & & 6.492 & \\
\hline & \multicolumn{2}{|c|}{ |---------------------------Ciclo 14-------------------------- } & \multicolumn{2}{|c|}{ |--------------------------Ciclo 15-------------------------- } \\
\hline BR 106 & 6.200 & 100 & 5.642 & 100 \\
\hline Progênies avaliadas & 7.125 & 112 & 6.767 & 120 \\
\hline Progênies selecionadas & 8.202 & 132 & 8.533 & 151 \\
\hline Amplitude de variação & $4.117-9.273$ & $66-150$ & $3.980-9.508$ & $70-169$ \\
\hline \multirow[t]{2}{*}{ Média ajustada } & 6.995 & & 7195 & \\
\hline & \multicolumn{2}{|c|}{---------------------------'Ciclo 16-------------------------- } & \multicolumn{2}{|c|}{ |---------------------------'Ciclo 17-------------------------- } \\
\hline BR 106 & 5.972 & 100 & 6.056 & 100 \\
\hline Progênies avaliadas & 7.380 & 124 & 7.273 & 120 \\
\hline Progênies selecionadas & 8.800 & 147 & 9.112 & 150 \\
\hline Amplitude de variação & $5.547-10.736$ & $93-180$ & $3.250-11.481$ & $54-190$ \\
\hline Média ajustada & 7.478 & & 7.287 & \\
\hline
\end{tabular}


razão da existência do componente de variação resultante da interação progênies x local, que não pode ser isolado.

Os coeficientes de herdabilidade, no sentido restrito, na média das progênies de meios-irmãos $\left(\mathrm{h}^{2} \mathrm{~m}\right)$, superaram os registrados na seleção massal $\left(\mathrm{h}^{2}\right)$ (Tabela 2), o que indica que a seleção com progênies de meios-irmãos deve ser mais eficiente que a seleção massal; isso concorda com Santos et al. (1998) e Carvalho et al. (2000b, 2003b, 2005a). Deve-se ressaltar, mais uma vez, que os valores mais altos foram encontrados nos ciclos realizados em um só local.

As magnitudes dos coeficientes de variação genética mostraram que a população 1 é a que apresenta maior variabilidade, que decresce depois nos ciclos subsequientes (Tabela 2). O decréscimo da variabilidade genética não é, entretanto, indicado na mesma proporção pela variância genética de meios-irmãos e pelos coeficientes de variação genética. Fato semelhante foi observado por Parteniani (1968), com as populações Piramex e Centralmex. Os valores dos coeficientes de variação genética obtidos refletem diferenças dos parâmetros genéticos entre as progênies, em todos os ciclos, e são mais relevantes no âmbito local. As estimativas dos índices b retratam uma situação mais favorável para a seleção nesse âmbito. Segundo Vencovsky \& Barriga (1992), uma situação muito favorável para a seleção de progênies de milhoé observada, quando a estimativa do índice b apresenta valor próximo ou superior à unidade.

Os ganhos estimados com a seleção, entre e dentro de progênies de meios-irmãos no ciclo 1, foram de 35\% (Tabela 2). Essa estimativa foi obtida pela seleção realizada em um só local. O ganho total estimado no ciclo 2 foi de 9,4\%. Esse decréscimo em relação ao ciclo 1 deve-se, principalmente, ao fato de esse ciclo ter sido realizado em dois locais. No ciclo 3 , a estimativa total do ganho esperado foi de $4,9 \%$, bastante inferior ao destacado no ciclo 17, em razão, provavelmente, da escassez de chuvas, que reduziu drasticamente as médias de produção de grãos das progênies, nesse ano agrícola.

Do ciclo 4 ao 17 de seleção, as estimativas mais elevadas dos ganhos com a seleção, entre e dentro das progênies, foram encontradas nos ciclos 4, 5, 7 e 17, em razão de esses ciclos terem sido realizados em apenas um local (Tabela 2). As estimativas do progresso genético esperado, nos últimos 11 ciclos de seleção, foram, em média, 7,2 e 3,3\%, entre e dentro de progênies, respectivamente, o que totaliza $10,5 \%$.

Após ajustar as médias dos ciclos de progênies avaliadas, para torná-las comparáveis, o ganho acumulado entre os ciclos 4 e 17 foi de $1.922 \mathrm{~kg} \mathrm{ha}^{-1}$ de espigas, equivalente a $35,82 \%$, o que fornece um ganho por ciclo/ano de $137 \mathrm{~kg} \mathrm{ha}^{-1}$ de espigas, que corresponde

Tabela 2. Estimativas obtidas em cada local e análises conjuntas, considerando-se os caracteres peso de grãos nos ciclos 1,2 e 3 , e peso de espigas nos demais ciclos de seleção, referentes à variância genética entre progênies $\left(\sigma_{\mathrm{p}}^{2}\right)$, variância genética aditiva $\left(\sigma_{\mathrm{A}}^{2}\right)$, variância de interação progênies x locais $\left(\sigma_{\mathrm{p} \times 1}^{2}\right)$, coeficiente de herdabilidade no sentido restrito de médias de progênies $\left(\mathrm{h}_{\mathrm{m}}^{2}\right)$, e quanto à seleção massal $\left(\mathrm{h}^{2}\right)$, coeficiente de variação genética $\left(\mathrm{CV}_{\mathrm{g}}\right)$, índices de variação $(\mathrm{b})$ e ganhos genéticos entre $\mathrm{e}$ dentro de progênies de meios-irmãos (Gs), com a variedade BR 5011 Sertanejo, na Região Nordeste do Brasil, de 1985 a 2001.

\begin{tabular}{|c|c|c|c|c|c|c|c|c|c|c|c|c|c|}
\hline \multirow[t]{2}{*}{ Ciclo } & \multirow[t]{2}{*}{ Local } & \multirow{2}{*}{$\sigma_{p}^{2}$} & \multirow{2}{*}{\multicolumn{2}{|c|}{$\begin{array}{c}\sigma_{\mathrm{A}}^{2} \\
\text { por planta) }{ }^{2}\end{array} \sigma_{\mathrm{p} \times 1}^{2}$}} & \multirow{2}{*}{$\mathrm{h}_{\mathrm{m}}^{2}$} & \multirow{2}{*}{$\begin{array}{c}h^{2} \\
--(\%)-\end{array}$} & \multirow{2}{*}{$\mathrm{CV}_{\mathrm{g}}$} & \multirow[t]{2}{*}{ b } & \multicolumn{2}{|c|}{ Gs entre } & \multicolumn{2}{|c|}{ Gs dentro } & \multirow{2}{*}{$\begin{array}{c}\text { Gs total } \\
(\%)\end{array}$} \\
\hline & & & & & & & & & g por planta & $\%$ & g por planta & $\%$ & \\
\hline 1 & 1 & 369,4 & 147,7 & - & 64,3 & 44,3 & 14,5 & 0,9 & 27,0 & 20,5 & 18,7 & 14,5 & 35,0 \\
\hline 2 & 2 & 77,8 & 311,2 & 65,4 & 35,7 & - & 6,3 & 0,4 & 7,3 & 6,6 & 3,8 & 2,8 & 9,4 \\
\hline 3 & 2 & 14,7 & 58,9 & 113,3 & 13,0 & - & 5,2 & 0,3 & 2,4 & 3,3 & 1,1 & 1,6 & 4,9 \\
\hline 4 & 1 & 213,5 & 854,0 & - & 52,8 & 21,2 & 12,0 & 1,0 & 18,6 & 11,1 & 8,9 & 5,3 & 16,4 \\
\hline 5 & 1 & 216,2 & 865,0 & - & 57,5 & 25,3 & 8,6 & 0,8 & 19,6 & 11,4 & 9,7 & 5,6 & 17,0 \\
\hline 6 & 2 & 47,0 & 188,0 & 320,8 & 17,6 & 2,1 & 4,4 & 0,4 & 5,0 & 3,3 & 1,3 & 0,9 & 4,2 \\
\hline 7 & 1 & 198,7 & 794,8 & - & 56,3 & 24,0 & 9,6 & 0,8 & 18,5 & 12,4 & 9,1 & 6,1 & 18,5 \\
\hline 8 & 3 & 42,8 & 171,1 & 109,9 & 36,0 & 3,7 & 5,5 & 0,4 & 6,9 & 5,8 & 1,7 & 1,5 & 7,3 \\
\hline 9 & 3 & 34,2 & 136,8 & 143,6 & 29,4 & 7,8 & 4,3 & 0,4 & 5,6 & 4,1 & 1,9 & 1,4 & 5,5 \\
\hline 10 & 2 & 6,6 & 26,4 & 100,8 & 10,0 & 3,0 & 2,8 & 0,3 & 1,7 & 1,6 & 0,6 & 0,6 & 2,2 \\
\hline 11 & 2 & 41,6 & 166,4 & 246,2 & 21,6 & 14,9 & 5,1 & 0,6 & 5,2 & 4,2 & 2,6 & 2,1 & 6,3 \\
\hline 12 & 2 & 45,2 & 180,8 & 12,9 & 11,1 & 7,8 & 5,4 & 0,4 & 7,4 & 5,9 & 2,2 & 1,8 & 7,7 \\
\hline 13 & 2 & 66,8 & 267,2 & 348,6 & 22,5 & 12,6 & 6,7 & 0,6 & 6,8 & 5,6 & 4,5 & 3,4 & 9,0 \\
\hline 14 & 3 & 158,8 & 635,2 & 391,0 & 45,6 & 19,6 & 9,2 & 0,7 & 14,9 & 10,9 & 4,8 & 3,5 & 14,4 \\
\hline 15 & 2 & 98,9 & 395,8 & 304,1 & 29,2 & 13,1 & 8,3 & 0,5 & 9,4 & 7,9 & 5,3 & 4,4 & 12,3 \\
\hline 16 & 2 & 52,5 & 210,2 & 92,2 & 27,3 & 3,9 & 5,7 & 0,4 & 6,6 & 5,2 & 2,7 & 2,1 & 7,3 \\
\hline 17 & 1 & 191,1 & 766,2 & - & 51,2 & 26,4 & 9,9 & 0,7 & 17,3 & 12,4 & 10,1 & 7,3 & 19,7 \\
\hline
\end{tabular}


a 2,56\%. Trabalhos relatados na literatura mostraram que existe concordância entre os valores dos progressos esperado e observado, por Webel \& Lonquist (1967), Paterniani (1968) e Sawazaki (1979).

\section{Conclusão}

As médias de produtividade e a magnitude das estimativas dos parâmetros genéticos mostram que a variedade BR 5011 Sertanejo possui alta variabilidade genética, tanto livre quanto potencial.

\section{Referências}

CARDOSO, M.J.; CARVALHO, H.W.L de; LEAL, M. de L da S.; SANTOS, M.X. dos. Melhoramento genético das cultivares de milho CMS 47 e BR 5039 (São Vicente) na Região Meio-Norte do Brasil. Revista Brasileira de Milho e Sorgo, v.2, p.88-96, 2003.

CARVALHO, H.W.L. de; GUIMARÃES, P.E. de O.; LEAL, M. de L. da S.; CARVALHO, P.C.L. de; SANTOS, M.X. dos. Avaliação de progênies de meios-irmãos da população de milho CMS 453 no Nordeste brasileiro. Pesquisa Agropecuária Brasileira, v.35, p.1577-1584, 2000b.

CARVALHO, H.W.L. de; LEAL, M. de L. da S.; SANTOS, M.X. dos. Estimativas de parâmetros genéticos na população de milho CMS 35 no Estado de Sergipe. Pesquisa Agropecuária Brasileira, v.37, p.1399-1405, 2002.

CARVALHO, H.W.L. de; LEAL, M. de L. da S.; SANTOS, M.X. dos. Estimativas de parâmetros genéticos na variedade de milho BR 5033 Asa Branca no Nordeste brasileiro. Revista Científica Rural, v.6, p.126-133, 2001.

CARVALHO, H.W.L. de; LEAL, M. de L. da S.; SANTOS, M.X. dos. Três ciclos de seleção entre e dentro de progênies de meiosirmãos na variedade de milho BRS Assum Preto. Revista Científica Rural, v.8, p.1-7, 2003b.

CARVALHO, H.W.L. de; LEAL, M. de L. da S.; SANTOS, M.X. dos; SOUZA, E.M. de. Estimativas dos parâmetros genéticos na população de milho CPATC-3 em dois locais de Sergipe. Pesquisa Agropecuária Brasileira, v.38, p.73-78, 2003c.

CARVALHO, H.W.L. de; SANTOS, M.X. dos; LEAL, M. de L. da S. Estimativas de parâmetros genéticos na população de milho CPATC-3 no Nordeste brasileiro. Agrotrópica, v.17, p.47-52, 2005 b.

CARVALHO, H.W.L. de; SANTOS, M.X. dos; LEAL, M. de L. da S.; CARVALHO, P.C.L. de. Melhoramento genético da cultivar de milho BR 5033-Asa Branca no Nordeste brasileiro. Pesquisa Agropecuária Brasileira, v.35, p.1417-1425, 2000a.

CARVALHO, H.W.L. de; SANTOS, M.X. dos; LEAL, M. de L. da S.; PACHECO, C.A.P. Melhoramento genético da variedade de milho BR 5028-São Francisco no Nordeste brasileiro. Pesquisa Agropecuária Brasileira, v.33, p.441-448, 1998.
CARVALHO, H.W.L. de; SANTOS, M.X. dos; LEAL, M. de L. da S.; SOUZA, E.M. de. Estimativas de parâmetros genéticos após três ciclos de seleção na variedade de milho BRS 5033-Asa Branca no Estado de Sergipe. Revista Científica Rural, v.10, p.95-101, 2005a.

CARVALHO, H.W.L. de; SANTOS, M.X. dos; LEAL, M. de L. da S.; SOUZA, E.M. de. Estimativas dos parâmetros genéticos de variedades de milho BR 5028-São Francisco no Nordeste brasileiro. Pesquisa Agropecuária Brasileira, v.38, p.929-935, $2003 \mathrm{a}$.

HALLAUER, A.R.; MIRANDA FILHO, J.B. Quantitative genetics in maize breeding. $2^{\text {nd }} \mathrm{ed}$. Ames: Iowa State University Press, 1988. 468p.

PACHECO, C.A.P. Avaliação de progênies de meios-irmãos na população de milho CMS 39 em diferentes condições de ambiente - 2º ciclo de seleção. 1987. 109p. Dissertação (Mestrado) - Escola Superior de Agricultura de Lavras, Lavras.

PACKER, D. Variabilidade genética e endogamia em quatro populações de milho (Zea mays L.). 1998. 100p. Dissertação (Mestrado) - Escola Superior de Agricultura Luiz de Queiroz, Piracicaba.

PATERNIANI, E. Avaliação de métodos de seleção entre e dentro de famílias de meios-irmãos no melhoramento de milho (Zea mays L.). 1968. 92p. Dissertação (Mestrado) - Escola Superior de Agricultura Luiz de Queiroz, Piracicaba.

RAMALHO, M.A.P. Eficiência relativa de alguns processos de seleção intrapopulacional no milho baseados em famílias não endógamas. 1977. 122p. Dissertação (Mestrado) - Escola Superior de Agricultura Luiz de Queiroz, Piracicaba.

SANTOS, M.X. dos; GUIMARÃES, P.E. de O.; PACHECO, C.A.P.; FRANÇA, G.E.; PARENTONI, S.N.; GAMA, E.E.G.; LOPES, M.A. Melhoramento intrapopulacional no sintético elite NT para solos pobres em nitrogênio. Pesquisa Agropecuária Brasileira, v.33, p.55-61, 1998.

SAWAZAKI, E. Treze ciclos de seleção entre e dentro de famílias de meios-irmãos para a produção de grãos no milho IAC Maia. 1979. 99p. Dissertação (Mestrado) - Escola Superior de Agricultura Luiz de Queiroz, Piracicaba.

SCAPIM, C.A.; CARVALHO, C.G.P.; CRUZ, C.D. Uma proposta de classificação dos coeficientes de variação para a cultura do milho. Pesquisa Agropecuária Brasileira, v.30, p.683-686, 1995.

VENCOVSKY, R. Herança quantitativa. In: PATERNIANI, E.; VIEGAS, G.P. Melhoramento e produção do milho. 2ed. Campinas: Fundação Cargill, 1987. p.137-214.

VENCOVSKY, R.; BARRIGA, P. Genética biométrica no fitomelhoramento. Ribeirão Preto: Sociedade Brasileira de Genética, 1992. 496p.

VIANNA, R.T.; SILVA, J.C. Comparação de três métodos estatísticos de análise de variância em experimentos em látice em milho (Zea mays L.). Experientiae, v.24, p.21-41, 1978.

WEBEL, O.D.; LONQUIST, J.H. An evalution of modified ear-torow selection in a population of corn (Zea mays L.). Crop Science, v.7, p.651-655, 1967.

$\overline{\text { Recebido em } 28 \text { de novembro de } 2006 \text { e aprovado em } 17 \text { de maio de } 2007}$ 